\title{
Relationship between water-holding capacity and intramuscular fat content in Japanese commercial pork loin
}

\author{
Genya Watanabe ${ }^{1, *}$, Michiyo Motoyama', Ikuyo Nakajima', and Keisuke Sasaki ${ }^{1}$
}

* Corresponding Author: Genya Watanabe Tel: +81-29-838-8690, Fax: +81-29-838-8606

E-mail: watanabeg080@affrc.go.jp

1 Institute of Livestock and Grassland Science, National Agriculture and Food Research Organization (NARO),

Tsukuba, Ibaraki 305-0901, Japan

ORCID

Genya Watanabe

https://orcid.org/0000-0001-8444-6525

Michiyo Motoyama

https://orcid.org/0000-0002-3587-8513

Ikuyo Nakajima

https://orcid.org/0000-0003-4508-356X

Keisuke Sasaki

https://orcid.org/0000-0002-9930-3356

Submitted Aug 30, 2017; Revised Oct 27, 2017; Accepted Dec 11, 2017
Objective: The relationship between water-holding capacity (WHC) and intermuscular fat (IMF) was studied in Japanese commercial pork.

Methods: Longissimus muscles of pigs $(\mathrm{n}=62)$, obtained from two meat packing plants, were analyzed for IMF content, moisture content, drip loss, cooking loss, and $\mathrm{pH}$. Pairwise relationships among these traits were determined using correlation analyses.

Results: IMF content was significantly correlated with moisture content $(r=-0.88 ; p<0.01)$ and $\mathrm{pH}(\mathrm{r}=0.32 ; \mathrm{p}<0.05)$, but not with drip loss $(\mathrm{r}=-0.23 ; \mathrm{p}=0.07)$ or cooking loss $(\mathrm{r}=$ $-0.10 ; \mathrm{p}=0.42$ ). In contrast, drip loss was significantly (and negatively) correlated with $\mathrm{pH}$ $(\mathrm{r}=-0.57 ; \mathrm{p}<0.01)$.

Conclusion: IMF content was not significantly correlated with WHC in pork, and so ultimately, we consider $\mathrm{pH}$ to be one of the most important factors influencing WHC in pork meat.

Keywords: Meat Quality; Pork; Water-holding Capacity; Drip Loss; Intramuscular Fat; pH

\section{INTRODUCTION}

The water-holding capacity (WHC) is the ability of meat to hold all or part of its water, and one of the most important traits of meat quality. Weight loss due to purge or drip loss ranges from $2 \%$ to $10 \%$ when meat is cut into chops [1]. These losses produce an economic cost to meat processors and retailers. In addition, drip loss is an important visual cue to assess meat quality. Some studies have suggested that consumers in most countries dislike drip loss in meat $[2,3]$.

In addition to WHC, intramuscular fat (IMF) contributes to meat quality. Aaslyng et al [4] suggested that juiciness experienced later in the chewing process was determined by a combination of the water content, IMF content and the saliva production during chewing of the pork. In addition, some studies have indicated a relationship between IMF content and the sensory traits of "juiciness" and "tenderness" in pork [5-8]. Consumer preference tests indicate that pork with an average IMF of $5.78 \%$ and $3.78 \%$ scores higher $(\mathrm{p}<0.05)$ eating acceptability than that with IMF of $<2.19 \%$ [6]. Given these preferences, genetic markers of meat with high IMF has been studied $[9,10]$. In addition, feeding approaches designed to increase IMF content have been studied; for example, a reduction in dietary lysine showed a significant increase (in the longissimus dorsi of pigs) in IMF content (6.7\%) relative to experimental controls (3.5\%) [11].

As described above, both WHC and IMF are important traits affecting the quality of pork, and so relationships between WHC and IMF have been extensively studied. Cannata et al [12] reported that pork loins of hybrid barrows (from Italy), with high visual marbling, scored a significantly lower drip loss than pork with low visual marbling, but there was no differ- 
ence in cooking loss. In contrast, pork loins of Large White and Landrace pigs (in Poland) with high fat content had higher cooking loss than pork with low fat content, but there was no difference in drip loss [13]. In addition, Huff-Lonergan et al [14] reported a significant positive correlation between lipid content and cooking loss in pork loin of F2 generations of Berkshire and Yorkshire pigs. If there is a relationship between the IMF and WHC, WHC might be improved by IMF content, however results of relationship between the IMF and WHC are not consistent among studies. Here, the IMF content of pork in previous studies mainly ranged between $1 \%$ and $4 \%$ $[12,13]$. In Japan, feeding technique of high IMF of pigs were reported [11] and some pig breeds were created which is based on the high IMF content [15]. Thus, there is a high interest in IMF of pork in Japan, and it is expected to investigate the relationship between IMF and WHC in pork with higher IMF content than previous studies. However, there is no information regarding the relationship between IMF content and WHC of pork obtained from three-way cross-bred Landrace $\times$ Large White $\times$ Duroc (LWD) pigs, which is the traditional, commercially produced breed in Japan. Therefore, in this study, we hypothesized that the relationship between IMF and WHC becomes clearer by analysis of pork produced in Japan (with a variety of IMF contents), and we investigated the IMF content, WHC and relating factors of WHC.

\section{MATERIALS AND METHODS}

\section{Samples}

Experiments were performed on samples of longissimus muscle obtained from 62 carcasses of finishing pigs slaughtered at the Ibaraki Kyodo meat Co., Ltd. (Tsuchiura, Japan) $(\mathrm{n}=32$; 18 females, 14 castrated males) and at the Tochigi prefectural animal husbandry Co., Ltd. (Utsunomiya, Japan) ( $\mathrm{n}=30 ; 16$ females, 14 castrated males). Carcasses weight was 67 to $87 \mathrm{~kg}$, with an average of $75 \mathrm{~kg}$. Loin samples were prepared at each meat plant, then refrigerated and delivered to our institute. All analyses were performed about $72 \mathrm{~h}$ after pigs were slaughtered.

\section{Drip loss}

Drip loss was determined using the suspension method of Honikel [16]. Longissimus muscle of the 13th to 15th thoracic vertebrae was used to measure drip loss. Each muscle was sliced to $2.0-\mathrm{cm}$ in thickness, and processed into a disk with a diameter of $4 \mathrm{~cm}$. Samples were put into netting and suspended in a plastic bag, ensuring that there was no contact between the sample and the bag. Samples were stored in this manner at $4^{\circ} \mathrm{C}$ for $24 \mathrm{~h}$. The weight of each slice was recorded before and after being suspended. Drip loss was expressed as a percentage of weight loss after suspension relative to the initial weight of the slice. Drip loss was measured in 3 replicate samples from each carcass, with the average value recorded as the drip loss for each sample.

\section{Cooking loss}

To determine cooking loss, longissimus muscle of 1st to 2nd lumbar vertebrae was processed in the same manner used for the drip loss experiment. Muscle disks were put into polyethylene bags and subjected to heat treatment using a water bath set at $95^{\circ} \mathrm{C}$ for cooking to an endpoint internal temperature of $75^{\circ} \mathrm{C}$. The internal temperature of each sample was monitored using a thermo recorder (TR-52S, T and D, Nagano, Japan). Thereafter, samples were chilled in crushed ice and held for $30 \mathrm{~min}$. Weight loss after cooking was calculated and expressed as the percentage of the weight before cooking. Cooking loss was measured using two replicates from each carcass and the average was recorded as the cooking loss for each sample.

\section{$\mathrm{pH}$}

Ultimate $\mathrm{pH}$ was measured directly on the surface of a cutting plane of the 13th thoracic vertebra at about $72 \mathrm{~h}$ after slaughter, using a pH meter (LAQUA D -71, Horiba, Kyoto, Japan) equipped with a flat, ion-sensitive, field-effect transistor electrode (0040-10D, Horiba, Japan). pH was measured in three replicates from each carcass and the average value was recorded as the $\mathrm{pH}$ for each sample.

\section{Intermuscular fat and moisture}

Samples were prepared from the longissimus muscle of the 11th to 12th thoracic vertebrae (ahead) and the 3 rd to 4 th lumbar vertebrae (backward). Measurements for IMF were conducted using the Soxhlet method, and moisture was measured using the atmospheric heating drying method. IMF and moisture content were analyzed by the Japan Food Research Laboratories (Tokyo, Japan). IMF and moisture content were recorded as the average of the ahead and backward samples because there was no difference in the IMF and moisture contents between the two samples using Student's t-test (data not shown).

\section{Statistical analysis}

Statistical analyses were performed using SAS (ver 9.4) (SAS Institute, Cary, NC, USA). Summary statistics for each trait were calculated using a MEANS procedure and the results of our 62 pork samples were summarized and compared with results from previous work on pork quality. Moreover, relationships between the traits were determined by calculating linear correlation using the CORR procedure.

\section{RESULTS AND DISCUSSION}

Summary statistics for each trait are shown in Table 1. In this 
Table 1. Summary of pork loin quality traits

\begin{tabular}{lcccccc}
\hline Traits & $\mathbf{n}$ & Average & Median & SD & Minimum & Maximum \\
\hline IMF (\%) & 62 & 3.59 & 3.55 & 1.40 & 0.80 & 7.15 \\
Moisture (\%) & 62 & 73.80 & 73.88 & 1.02 & 70.60 & 75.95 \\
pH $^{11}$ & 60 & 5.93 & 5.93 & 0.14 & 5.71 & 6.29 \\
Drip loss (\%) & 62 & 2.89 & 2.41 & 1.55 & 1.00 & 7.62 \\
Cooking loss (\%) & 62 & 23.00 & 23.48 & 2.70 & 16.85 & 28.90 \\
\hline
\end{tabular}

SD, standard deviation; IMF, intermuscular fat.

1) Due to problems with electrode, $n=60$.

study, the range in IMF content was 0.80 to 7.15 , with an average of $3.59 \%$. Daszkiewicz et al [13] found that IMF was $\leq 2 \%$ for most (83.78\%) samples in their study of the relationships between IMF content and meat quality traits of 74 pork loins [13]. Font-i-Furnols et al [7] reported a range in IMF content from $0.53 \%$ to $5.98 \%$. Therefore, IMF content revealed in this study was slightly higher and the range was wider than literature in previous studies. Moisture content was $73.80 \%$, which was similar to some studies $[8,17,18]$. The $\mathrm{pH}$ in our study was 5.93, which was higher that the $\mathrm{pH}$ range (5.65 to 5.83) in previous studies $[8,14,19]$. These studies measured an internal $\mathrm{pH}$ by glass electrode; however, we measured a surface $\mathrm{pH}$ by ionsensitive field-effect transistor electrode because this electrode could measure $\mathrm{pH}$ by without destruction of pork. The type of electrode used in this study is probably responsible for the slight difference in $\mathrm{pH}$ data. In addition, Doherty et al [20] demonstrated that surface $\mathrm{pH}$ by combination electrode was significantly higher than internal $\mathrm{pH}$ on lamb loin by glass electrode. Therefore, the high $\mathrm{pH}$ of pork presented in this study might also be due to differences between internal and surface.

Drip loss was $2.89 \%$, which was similar to previous studies using the same suspension method $[12,19]$. Cooking loss was $23.0 \%$, which was almost the same magnitude of loss as previous studies; however simple comparisons could not be made because the heating treatment procedures differed among studies [8,14,21].

Pearson correlation coefficients are shown in Table 2. IMF content was significantly (and negatively) correlated with moisture content $(\mathrm{r}=-0.88 ; \mathrm{p}<0.01)$. It is generally accepted that moisture content of beef correlates negatively with fat content

Table 2. Pearson correlation coefficients between IMF, moisture, pH, drip loss and cooking loss of pork

\begin{tabular}{lccccc}
\hline Item & IMF & Moisture & pH & Drip loss & Cooking loss \\
\hline IMF & 1 & $-0.88^{* *}$ & $0.32^{*}$ & -0.23 & -0.10 \\
Moisture & - & 1 & -0.13 & 0.19 & 0.16 \\
pH & - & - & 1 & $-0.57^{* *}$ & -0.13 \\
Drip loss & - & - & - & 1 & $0.34^{* *}$ \\
Cooking loss & - & - & - & - & 1 \\
\hline
\end{tabular}

IMF, intermuscular fat.

${ }^{* *} p<0.01,{ }^{*} p<0.05$.
[22,23]. Likewise, moisture is replaced by fat in pork as well.

As shown in Table 2, IMF content was not significantly correlated with drip loss $(\mathrm{r}=-0.23 ; \mathrm{p}=0.07)$ or cooking loss ( $\mathrm{r}$ $=-0.10 ; \mathrm{p}=0.42)$. Cannata et al [12] reported a significant negative correlation between lipid content of meat and cooking loss. In contrast, Huff-Lonergan et al [14] found a significant positive correlation between total lipid content and cooking loss. Here, in this study, there was no significant correlation between the IMF and the WHC even if the LWD which had a higher IMF than previous studies. Thus, relationship between IMF content and WHC are not consistent among studies, including our own.

On the other hand, the physical factors might be affect to WHC. The majority of moisture in muscle is held within the structure of the muscle and muscle cells [24]. $\mathrm{pH}$ fall of post mortem induced myosin denaturation $[25,26]$ and an increase in extracellular spaces [27], both of which increase drip loss. In our study, $\mathrm{pH}$ was significantly and negatively correlated with drip loss, a finding similar to the results of previous studies using a wide variety of pig breeds [14,28-30]. Therefore, it has been suggested that the effect of $\mathrm{pH}$ on WHC is greater than effect of IMF content on WHC. On the other hand, high postmortem temperature also induces protein denaturation and increases the amount of extracellular spaces, which then increase drip loss [25,31]. Post-mortem temperatures in meat plants and on delivery trucks were not controlled in this study. Thus, slight differences in post-mortem temperature might have affected the WHC in our study. Moreover, pre-slaughter stress may increase early post-mortem temperatures, cause declines in $\mathrm{pH}$, and increase drip losses of the longissimus dorsi in pigs [32]. Changes in these physical factors contribute to WHC and so may have influenced the relationship between IMF and WHC in our study.

Nutritional factors might also affect IMF and WHC. The IMF content of pork loin is significantly increased by reductions in protein intake [33] or lysine intake [34]; however, WHC did not differ in these studies. In addition, supplementing the diet of pigs with vitamin $\mathrm{E}$ decreases drip loss in pork [35]. As described above, both IMF and WHC are affected by nutritional effects. However, the nutritional content of feed consumed by pigs in our study is not known. Therefore, differences in nutritional factors could have influenced the relationship between IMF and drip loss in our study.

In conclusion, IMF was not significantly correlated with WHC, and the correlation between $\mathrm{pH}$ and WHC was higher than the correlation between IMF and WHC in LWD breeds, which is the most common breed produced in Japan. Therefore, it was suggested that it is difficult to improve WHC by only increasing of IMF content, and $\mathrm{pH}$ control is more important for improving WHC than IMF content. Because both IMF and WHC are important characteristics for meat quality, it is necessary to improve them respectively by management 
of such as a slaughter stress, post-mortem temperatures, and nutritional factors.

\section{CONFLICT OF INTEREST}

We certify that there is no conflict of interest with any financial organization regarding the material discussed in the manuscript.

\section{ACKNOWLEDGMENTS}

This study was financially supported in part by a grant from the Science and Technology Research Promotion Program for Agriculture, Forestry, Fisheries, and Food Industry (27005B) of the Ministry of Agriculture, Forestry and Fisheries, Japan. The authors sincerely thank Yumiko Endo and Yuko Kurosawa, Institute of Livestock and Grassland Science, NARO, for their generous assistance.

\section{REFERENCES}

1. Offer G, Knight P. The structural basis of water-holding in meat. Part 2: drip losses. In: Lawrie R, editor. Development in meat science, Vol. 4. London, UK: Elsevier Science Publications; 1988. p. 173-243.

2. Ngapo TM, Martin JF, Dransfield E. International preferences for pork appearance: I. Consumer choices. Food Qual Prefer 2007;18:26-36.

3. Verbeke W, De Sme S, Vackier I, et al. Role of intrinsic search cues in the formation of consumer preferences and choice for pork chops. Meat Sci 2005;69:343-54.

4. Aaslyng MD, Bejerholm C, Ertbjerg P, Bertram HC, Andersen HJ. Cooking loss and juiciness of pork in relation to raw meat quality and cooking procedure. Food Qual Prefer 2003;14;27788.

5. DeVol DL, McKeith FK, Bechtel PJ, et al. Variation in composition and palatability traits and relationships between muscle characteristics and palatability in a random sample of pork carcasses. J Anim Sci 1988;66:385-95.

6. Fernandez X, Monin G, Talmant A, Mourot J, Lebret B. Influence of intramuscular fat content on the quality of pig meat - 1. Composition of the lipid fraction and sensory characteristics of $m$. longissimus lumborum. Meat Sci 1999;53:59-65.

7. Font-i-Furnols M, Tous N, Esteve-Garcia E, Gispert M. Do all the consumers accept marbling in the same way? The relationship between eating and visual acceptability of pork with different intramuscular fat content. Meat Sci 2012;91:448-53.

8. Rincker PJ, Killefer J, Ellis M, Brewer MS, McKeith FK. Intramuscular fat content has little influence on the eating quality of fresh pork loin chops. J Anim Sci 2008;86:730-7.

9. Newcom DW, Baas TJ, Schwab CR, Stalder KJ. Genetic and phenotypic relationships between individual subcutaneous backfat layers and percentage of longissimus intramuscular fat in Duroc swine. J Anim Sci 2005;83:316-23.

10. Gerbens F, van Erp AJ, Harders FL, et al. Effect of genetic variants of the heart fatty acid-binding protein gene on intramuscular fat and performance traits in pigs. J Anim Sci 1999; 77:846-52.

11. Katsumata M, Kobayashi S, Matsumoto M, Tsuneishi E, Kaji Y. Reduced intake of dietary lysine promotes accumulation of intramuscular fat in the Longissimus dorsi muscles of finishing gilts. Anim Sci J 2005;76:237-44.

12. Cannata S, Engle TE, Moeller SJ, et al. Effect of visual marbling on sensory properties and quality traits of pork loin. Meat Sci 2010;85:428-34.

13. Daszkiewicz T, Bąk T, Denaburski J. Quality of pork with a different intramuscular fat (IMF) content. Pol J Food Nutr Sci 2005;14/55:31-6.

14. Huff-Lonergan E, Baas TJ, Malek M, et al. Correlations among selected pork quality traits. J Anim Sci 2002;80:617-27.

15. Irie M. Quality and evaluation for pork. J Anim Genet (Doubutsu Iden Ikusyu Kenkyu) 2006;34:33-44.

16. Honikel KO. Moisture and water-holding capacity. In: Nollet LML, Toldra F, editors. Handbook of muscle foods analysis. Boca Raton, FL, USA: CRC Press; 2009. p. 315-34.

17. Nold RA, Romans JR, Costello WJ, Libal GW. Characterization of muscles from boars, barrows, and gilts slaughtered at 100 or 110 kilograms: differences in fat, moisture, color, waterholding capacity, and collagen. J Anim Sci 1999;77:1746-54.

18. Kim JH, Seong PN, Cho SH, et al. Characterization of nutritional value for twenty - one pork muscles. Asian-Australas J Anim Sci 2008;21:138-43.

19. Lee SH, Choe JH, Choi YM, et al. The influence of pork quality traits and muscle fiber characteristics on the eating quality of pork from various breeds. Meat Sci 2012;90:284-91.

20. Doherty AM, Sheridan JJ, Allen P, McDowell DA, Blair IS. Physical characteristics of lamb primals packaged under vacuum or modified atmospheres. Meat Sci 1996;42:315-24.

21. Boler DD, Dilger AC, Bidner BS, et al. Ultimate $\mathrm{pH}$ explains variation in pork quality traits. J Muscle Foods 2010;21:119-30.

22. Savell JW, Cross HR, Smith GC. Percentage ether extractable fat and moisture content of beef Longissimus muscle as related to USDA marbling score. J Food Sci 1986;51:838-9.

23. Ueda Y, Watanabe A, Higuchi M, et al. Effects of intramuscular fat deposition on the beef traits of Japanese Black steers (Wagyu). Anim Sci J 2007;78:189-94.

24. Offer $\mathrm{G}$, Cousins $\mathrm{T}$. The mechanism of drip production: formation of two compartments of extracellular-space in muscle post mortem. J Sci Food Agric 1992;58:107-16.

25. Penny IF. Protein denaturation and water holding in pork muscle. Int J Food Sci Technol 1969;4:269-73.

26. Offer G. Modelling of the formation of pale, soft and exudative meat: effects of chilling regime and rate and extent of glycolysis. Meat Sci 1991;30:157-84. 
27. Guignot F, Vignon X, Monin G. Post mortem evolution of myofilament spacing and extracellular space in veal muscle. Meat Sci 1993;33:333-47.

28. Bidner BS, Ellis M, Brewer MS, et al. Effect of ultimate $\mathrm{pH}$ on the quality characteristics of pork. J Muscle Foods 2004;15: 139-54.

29. Geesink GH, Schreutelkamp FH, Frankhuizen R, et al. Prediction of pork quality attributes from near infrared reflectance spectra. Meat Sci 2003;65:661-8.

30. Prevolnik M, Candek-Potokar M, Novič M, Skorjanc D. An attempt to predict pork drip loss from $\mathrm{pH}$ and colour measurements or near infrared spectra using artificial neural networks. Meat Sci 2009;83:405-11.

31. Penny IF. The effect of temperature on the drip, denatura- tion and extracellular space of pork longissimus dorsi muscle. J Sci Food Agric 1977;28:329-38.

32. Rosenvold K, Andersen HJ. The significance of pre-slaughter stress and diet on colour and colour stability of pork. Meat Sci 2003;63:199-209.

33. Goerl KF, Eilert SJ, Mandigo RW, Chen HY, Miller PS. Pork characteristics as affected by two populations of swine and six crude protein levels. J Anim Sci 1995;73:3621-6.

34. Hyun Y, Kim JD, Ellis M, et al. Effect of dietary leucine and lysine levels on intramuscular fat content in finishing pigs. Can J Anim Sci 2007;87:303-6.

35. Buckley DJ, Morrissey PA, Gray JI. Influence of dietary vitamin E on the oxidative stability and quality of pig meat. J Anim Sci 1995;73:3122-30. 